\title{
Methane dehydroaromatisation and methanol activation over zeolite catalysts: an overview
}

\author{
J. S. J. Hargreaves ${ }^{1}$
}

Received: 5 January 2016/ Accepted: 17 May 2016/Published online: 2 June 2016

(c) The Author(s) 2016. This article is published with open access at Springerlink.com

\begin{abstract}
A brief overview of methane dehydroaromatisation over $\mathrm{MoO}_{3} / \mathrm{H}-\mathrm{ZSM}-5$ derived catalysts, the deposition of carbonaceous residues from methanol over H-mordenite and the role of binders in zeolite catalysed reactions is presented. The selective poisoning of methane cracking catalysts is proposed as a potential strategy for the development of methane dehydroaromatisation catalysts. In the case of methanol conversion over H-mordenite, evidence is presented for the formation of larger alkylated aromatics, such as methylnaphthalenes. Binders, ubiquitous components of technical catalysts, have been documented to have a number of important effects often outweighing laboratory based modifications, and therefore, consideration of their effects should be made at an early stage of catalyst development.
\end{abstract}

Keywords Binder Methane Methanol - Mordenite . Zeolite $\cdot$ ZSM-5

\section{Introduction}

Zeolites are widely applied in heterogeneous catalysis [1]. In addition to the advantages offered through reactant, product or transition state selectivity, they are versatile and durable catalysts which can function as acid catalysts in their own right where the nature and strength of acid sites can be carefully tuned through, for example, pretreatment and control of their Si/Al ratio. They also find application as supports for active catalytic phases where their regular

\section{J. S. J. Hargreaves}

justinh@chem.gla.ac.uk

1 WestCHEM, School of Chemistry, Joseph Black Building, University of Glasgow, Glasgow G12 8QQ, UK and highly defined pore structure can be used to control dispersion and their acidity can lend bifunctional behaviour to reactions of interest. In this brief overview, examples of the application of zeolites as active components of heterogeneous catalysts for the conversion of a selected range of small molecules-methane and methanol—will be outlined. In the case of methane, catalysts generated from $\mathrm{MoO}_{3} / \mathrm{H}-\mathrm{ZSM}-5$ will be described, whereas for methanol conversion, the nature of the carbonaceous deposits generated over mordenite will be considered. Finally, consideration will be directed towards the role of binders in zeolite catalysed reactions, which while of vital importance in the development and application of technical catalysts for commercial application, is an aspect seldom considered in academic studies although recently there has been a greater awareness of its importance.

\section{Dehydroaromatisation of methane}

Methane, which is the major component of natural gas, is the most inert alkane. There has been interest in its conversion into products which are more valuable and/or more easily transportable [2]. In general, it is an indirect feedstock for the production of various target products through its conversion to syn gas by steam reforming and associated technologies. The possibility of syn gas generation via the reaction of methane directly with $\mathrm{CO}_{2}$, the so-called dry reforming reaction is also of interest based upon the desirability of co-reacting two greenhouse gases [3]. For a great number of years, the possibility of more direct conversion routes from methane has attracted interest and the development of catalysts exhibiting appropriate productivity and lifetime has been a major goal. Oxidative coupling, wherein higher hydrocarbons (specifically ethylene) are generated has been strongly targeted [4], as has direct 
partial oxidation to yield methanol or formaldehyde in a single step [5]. More recently, dehydroaromatisation has been the subject of some attention [6,7]. This reaction which can be summarised by the following stoichiometric equation:

$6 \mathrm{CH}_{4} \rightarrow \mathrm{C}_{6} \mathrm{H}_{6}+9 \mathrm{H}_{2}$

can be facilitated by catalysts derived from $\mathrm{MoO}_{3} / \mathrm{H}-\mathrm{ZSM}-5$ or $\mathrm{MoO}_{3} / \mathrm{H}-\mathrm{MCM}-22$. At $700{ }^{\circ} \mathrm{C}$, which is a typical reaction temperature employed, methane conversion is limited to ca. $11 \%$ and the reaction is generally operated at low space velocity. It is generally accepted that the $\mathrm{MoO}_{3}$ component is transformed into molybdenum carbide or oxycarbide clusters upon reaction $[8,9]$ and that these may be dispersed within the zeolite pore structure, with the medium pore zeolites ZSM-5 and MCM-22 being most effective in terms of catalytic performance. The most widely accepted mechanism is based upon initial dehydrogenative coupling of methane to form ethylene as a primary product which often forms part of the reaction product stream, and subsequent acid catalysed conversion of ethylene to the aromatic product [10]. In terms of such a mechanism, it might be imagined that the former step is more closely associated with the carbide/ oxycarbide component with parallels often being drawn between the catalytic behaviour of molybdenum carbide and precious metals although these might be overstated [11] and the latter step the zeolite component.

A number of studies have evidenced the migration of the $\mathrm{MoO}_{3}$ component into the zeolite pore structure. For example, the $\mathrm{Mo} / \mathrm{Si}$ ratios determined by XPS in elucidating the possible dispersion of molybdenum nitride clusters within H-ZSM-5 from $\mathrm{MoO}_{3} / \mathrm{H}-\mathrm{ZSM}-5$ suggest redistribution of the Mo species upon nitridation [12, 13]. In situ FTIR studies following thermal activation of $\mathrm{MoO}_{3} /$ H-ZSM-5 evidence loss of $\mathrm{OH}$ features at 3733, 3613 and $3440 \mathrm{~cm}^{-1}$ corresponding to terminal $\mathrm{OHs}$, bridging $\mathrm{OHs}$ and hydroxyl nests, respectively [13]. Figure 1 presents an in situ FTIR study of the activation of $\mathrm{MoO}_{3} / \mathrm{H}-\mathrm{ZSM}-5$ in vacuo as detailed elsewhere [13]. The insets show the rates of loss of the 3613 and $3440 \mathrm{~cm}^{-1}$ bands as a function of temperature. Upon high temperature activation, the only $\mathrm{OH}$ groups still present correspond to those with bands at 3744 and $3610 \mathrm{~cm}^{-1}$. It is known that excessive heat treatment can have deleterious effects upon catalytic performance through dealumination of the zeolite framework and the formation of aluminium molybdate which can be identified in ${ }^{27} \mathrm{Al}$ MAS NMR studies as evidenced by bands at -14 and/or $+14 \mathrm{ppm}$ (corresponding to anhydrous and hydrated aluminium molybdate, respectively [14]). Indeed, the molybdenum species perturb the local environment of the $\mathrm{Al}$ in the framework as has been demonstrated by the application of Al EXAFS [15]. Table 1 presents the results of Al XAS studies upon

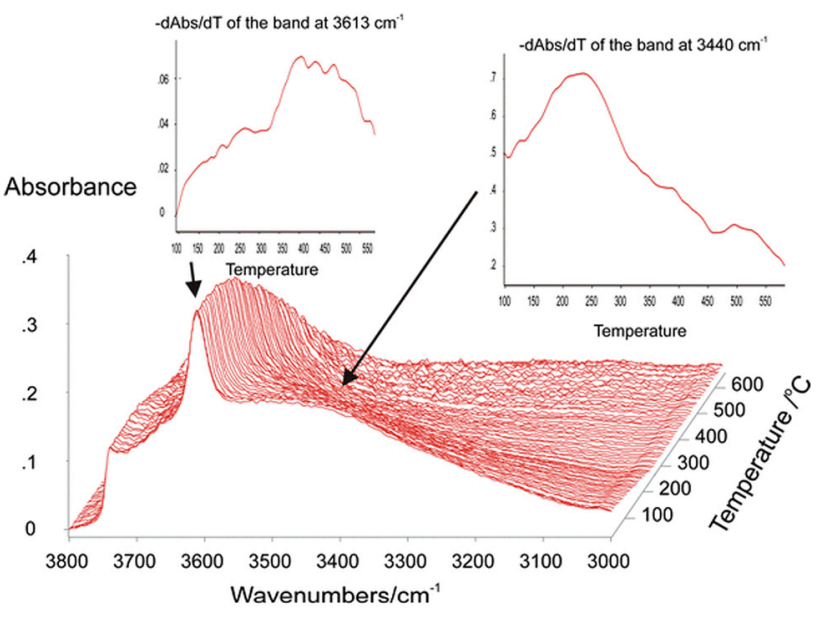

Fig. 1 FTIR spectra of the activation of $\mathrm{MoO}_{3} / \mathrm{H}-\mathrm{ZSM}-5$ in vacuo with insets showing the removal rates of bridging groups and hydroxyl nests (3613 and $3440 \mathrm{~cm}^{-1}$, respectively.) Figure reproduced from Ref. [13] with very kind permission from Springer

Table 1 Structural parameters for activated MoO3/H-ZSM-5 determined from Al K-edge XAS studies as outlined in Ref. [15]

\begin{tabular}{lll}
\hline & $r(\AA)$ & DW $\left(\AA^{2}\right)$ \\
\hline Al-O & 1.76 & 0.001 \\
Al-O & 1.65 & 0.001 \\
Al-O & 1.73 & 0.001 \\
Al-O & 1.89 & 0.001 \\
Al-Si average & 3.09 & 0.006 \\
\hline
\end{tabular}

activated $\mathrm{MoO}_{3} / \mathrm{H}-\mathrm{ZSM}-5$ for which ${ }^{27} \mathrm{Al}$ MAS NMR shows the presence of only a small amount of extraframework Al. From this data, it can be seen that there are a distribution of $\mathrm{Al}$ distances which is consistent with other studies [16]. Furthermore, the long Al-O distance (1.89 A) is significantly shorter than it has been found to be $(1.98 \AA)$ in the studies of H-ZSM-5 [16]. As discussed elsewhere, there have been correlations made between the "long" Al$\mathrm{O}$ bond length and acid site strength for H-ZSM-5 [16]. Interestingly, $\mathrm{NH}_{3}$ TPD undertaken on activated $\mathrm{MoO}_{3} / \mathrm{H}-$ ZSM-5 suggests a reduction in acid site strength as compared to the parent H-ZSM-5 as shown in Fig. 2, where a ca. $50{ }^{\circ} \mathrm{C}$ reduction of the temperature maximum of the high temperature desorption feature corresponding to the interaction of $\mathrm{NH}_{3}$ with the Bronsted acid sites is evident (the two lower temperature features corresponding to weakly adsorbed $\mathrm{NH}_{3}$ and that interacting with silanol groups) [15]. Figure 3 presents the difference FTIR spectrum of the adsorbed $\mathrm{NH}_{3}$ over the activated $\mathrm{MoO}_{3} / \mathrm{H}-$ ZSM-5, where the loss of the ca $3600 \mathrm{~cm}^{-1}$ feature and the growth of the $1460 \mathrm{~cm}^{-1}$ feature corresponds to the consumption of bridging $\mathrm{OHs}$ and the formation of $\mathrm{NH}_{4}{ }^{+}$ species, respectively. 
Fig. $2 \mathrm{NH}_{3}$ TPD profiles of: a parent $\mathrm{H}-\mathrm{ZSM}-5$ and $\mathbf{b} 3 \mathrm{wt} \%$ $\mathrm{MoO}_{3} / \mathrm{H}-\mathrm{ZSM}-5$ activated by calcination in air at $500{ }^{\circ} \mathrm{C}$ for $16 \mathrm{~h}$. Figure reproduced form Ref. [15] with very kind permission from Elsevier
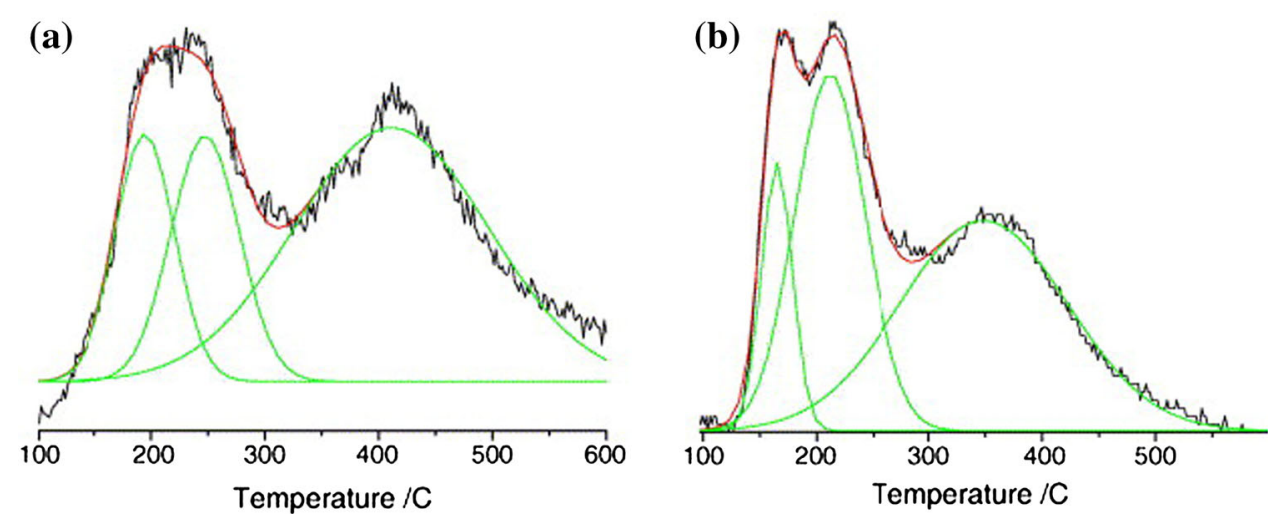

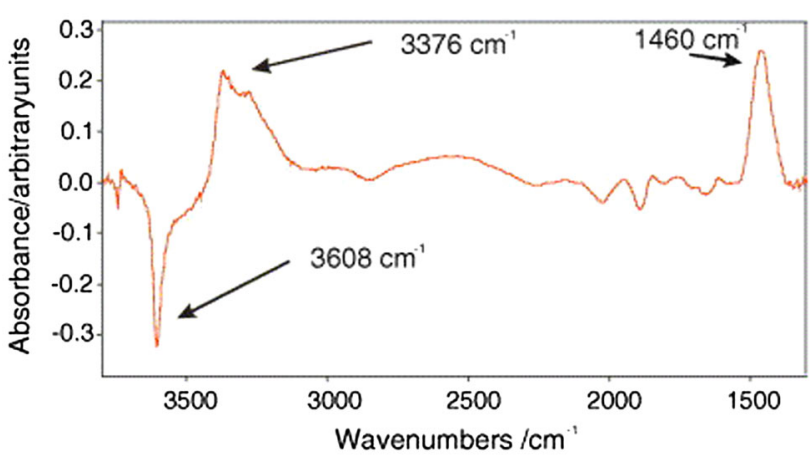

Fig. 3 Difference FTIR spectrum between 3 wt $\% \mathrm{MoO}_{3} / \mathrm{H}-\mathrm{ZSM}-5$ in contact with $10^{-2}$ mbar $\mathrm{NH}_{3}$ and the activated sample. Figure reproduced form Ref. [15] with very kind permission from Elsevier

Figure 4 presents a typical reaction profile showing the benzene formation rate for activated $\mathrm{MoO}_{3} / \mathrm{H}-\mathrm{ZSM}-5$ exposed to methane at $700{ }^{\circ} \mathrm{C}$ in which the initial activation is evident during which transformation of the molybdenum species occurs followed by gradual deactivation [17]. Within the literature, a number of studies have sought to improve catalyst performance and retard catalyst deactivation by the inclusion of low levels of dopants (such as $\mathrm{Fe}$ and $\mathrm{Co}$ [18]) or gas-phase additives (such as $\mathrm{CO}$ or $\mathrm{CO}_{2}$ [19].) Whilst $\mathrm{C}_{6} \mathrm{H}_{6}$ is the major aromatic product, higher aromatics have been reported to be formed, albeit in much lower concentration [20]. As mentioned above, ethylene is frequently observed as a component of the product stream. Although some studies have done so, it is perhaps very surprising that so little attention has been given to the production of hydrogen, especially when it is considered that it is the major stoichiometric product of reaction. Its formation rate is also included in Figs. 4 and 5 presents the $\mathrm{H}_{2}: \mathrm{C}_{6} \mathrm{H}_{6}$ formation rate ratio corresponding to this data. It can be seen that the ratio significantly exceeds the value of 9 which would be expected on the basis of totally selective conversion. This is indicative of side product formation and a significant part of this discrepancy can be attributed to non-selective $\mathrm{c}$ racking of methane:

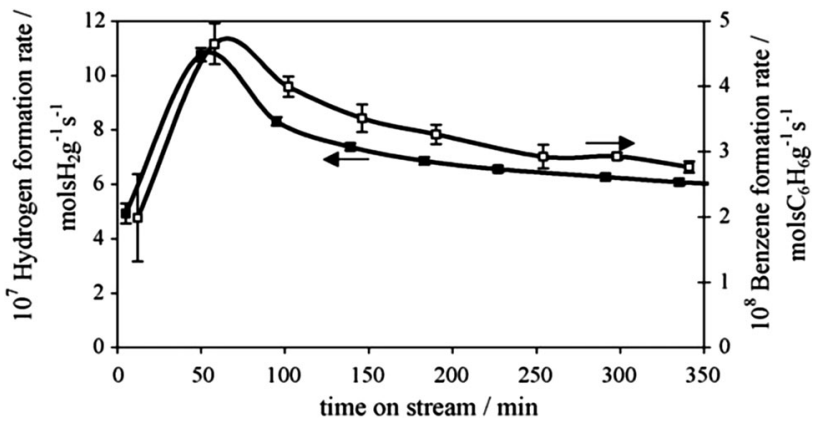

Fig. 4 Benzene and hydrogen formation rates as a function of time on stream for $3 \mathrm{wt} \% \mathrm{MoO}_{3} / \mathrm{H}-\mathrm{ZSM}-5$. Figure reproduced from Ref. [17] with very kind permission from Elsevier

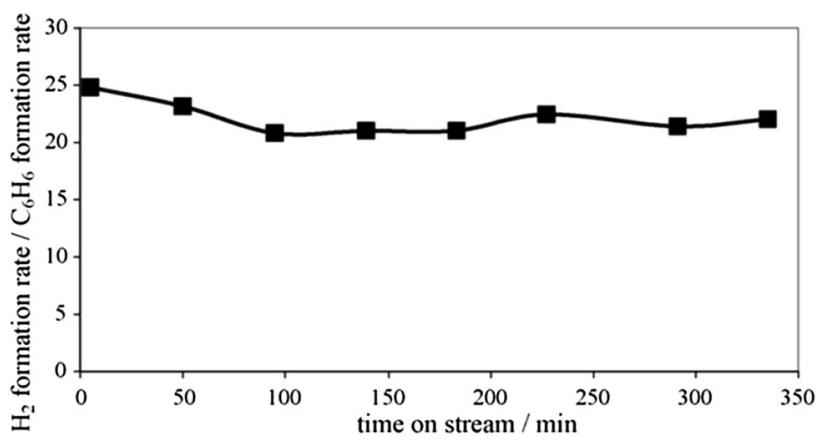

Fig. 5 The ratio of $\mathrm{H}_{2}$ to $\mathrm{C}_{6} \mathrm{H}_{6}$ corresponding to Fig. 4 as a function of time on stream. Figure reproduced from Ref. [17] with very kind permission from Elsevier

$\mathrm{CH}_{4} \rightarrow \mathrm{C}+2 \mathrm{H}_{2}$

XPS analysis of spent catalysts evidences a range of carbonaceous species-carbidic, hydrogen poor sp type carbon associated with catalyst deactivation present upon the external catalyst surface and graphitic [21]. In terms of the latter components, it is interesting to note that TEM studies as shown in Fig. 6 have demonstrated that some of the coke should be attributed to carbon nanotubes [22].

The above discussion briefly summarises some of the aspects of importance for the $\mathrm{MoO}_{3} / \mathrm{H}-\mathrm{ZSM}-5$ methane

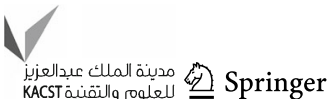




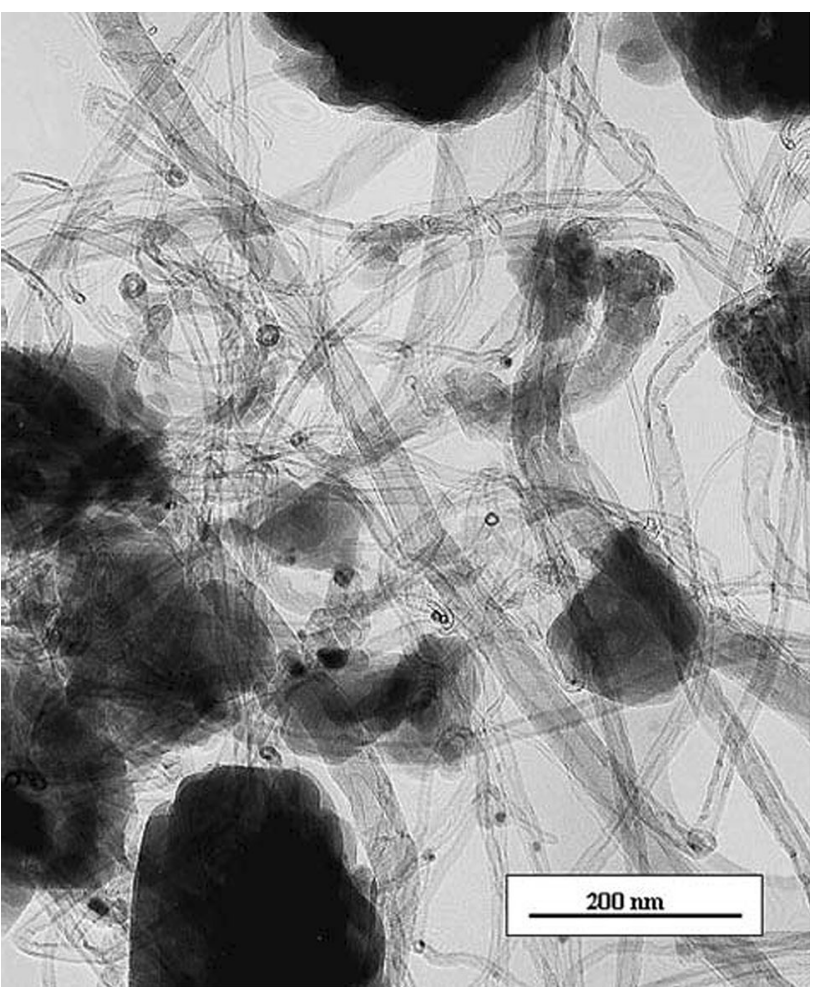

Fig. 6 TEM of post-reaction $\mathrm{Fe}^{3+}-\mathrm{MoO}_{3} / \mathrm{H}-\mathrm{ZSM}-5$ following $6.5 \mathrm{~h}$ on stream for methane dehydroaromatisation at $700{ }^{\circ} \mathrm{C}$ showing a region with a high density of carbon nanotubes. Figure reproduced from Ref. [22] with very kind permission from Springer

dehydroaromatisation catalyst system. Whilst alternative active catalysts are known, such as $\mathrm{Fe}$ and Re containing zeolitic systems; and strategies, such as the application of membrane technology, catalyst doping and modified catalyst preparation routes can be used to improve performance, further improvements in methane dehydroaromatisation are necessary. Taken together, the observations in the preceding paragraph can lead to the non-conventional view that the $\mathrm{MoO}_{3} / \mathrm{H}-\mathrm{ZSM}-5$ derived catalyst is a poorly active catalyst for methane cracking with the gas-phase aromatic content corresponding to "gasphase coke" which has failed to condense as in the case of a more active methane cracking catalyst, or alternatively it could be unconventionally considered a longer lifetime methane cracking catalyst where loss of (potential) deactivating coking residue through the gas-phase can lead to catalysts of longer lifetime. Figure 7, taken from Ref. [23], shows thermodynamic data for both processes. Furthermore, upon comparing the observed hydrogen formation rates between dehydroaromatisation and cracking that for $3 \mathrm{wt} \% \mathrm{MoO}_{3} / \mathrm{H}-\mathrm{ZSM}-5$ (which undergoes a mixture of dehydroaromatisation and coking) attains ca $8 \times 10^{-7}$ mol g $\mathrm{s}^{-1}$ compared to ca $50 \times 10^{-7} \mathrm{~mol} \mathrm{~g}^{-1} \mathrm{~s}^{-1}$ for methane cracking over $3 \mathrm{wt} \% \mathrm{Pd} / \mathrm{H}-\mathrm{ZSM}-5$ at $700{ }^{\circ} \mathrm{C}$ under directly comparable conditions [22].
With the above aspects in mind, it may be the case that a better strategy for the development of more highly methane dehydroaromatisation catalysts is, rather than attempting to promote the comparatively low activity $\mathrm{MoO}_{3} / \mathrm{H}-\mathrm{ZSM}-5$ system, selective poisoning/modification of highly active methane cracking catalysts.

\section{Methanol to hydrocarbons}

In recent years, there has been renewed interest in the catalytic conversion of methanol to hydrocarbons. Various zeolites and zeotypes are known to be active for this reaction. Arguably, SAPO-34 is of most interest when the target products are lower olefins (MTO — an interesting alternative to energy intensive steam cracking routes) and H-ZSM-5 for gasoline range hydrocarbons (MTH) [24, 25]. The so-called hydrocarbon pool mechanism, wherein an active hydrocarbonaceous pool is the source of activity, has gained widespread acceptance in this reaction [25-27]. As reviewed in detail elsewhere, the exact nature of the hydrocarbon pool and its formation is under refinement and it may depend upon the nature of framework with larger hydrocarbonaceous species occurring in the case of larger pore zeolites and zeotypes. The temperature at which reaction selectivity is switched between the simple dehydration product, dimethyl ether, and hydrocarbons is a strong function of $\mathrm{Si} / \mathrm{Al}$ ratio and reflects the temperature at which the active pool is formed. Historically, MTH was operated in New Zealand at the scale of 600,000 tonnes per year, but the process was discontinued - the temperature of operation was ca. $400{ }^{\circ} \mathrm{C}$ [24]. MTO is also operated on a commercial scale. The development of carbonaceous residues from the reaction of methanol over mordenite has been investigated [28].

When reacted for $5 \mathrm{~h}$ at 300 and $500{ }^{\circ} \mathrm{C}$, respectively, the nature of the carbonaceous deposit was found to differ. In the case of the sample generated at $500{ }^{\circ} \mathrm{C}$, the carbonaceous residue was harder as evidenced by the temperature programmed oxidation and ${ }^{13} \mathrm{C}$ MAS NMR studies. In the case of the sample generated at $300{ }^{\circ} \mathrm{C}$, there were additional features present in both the temperature programmed oxidation profile and also in the ${ }^{13} \mathrm{C}$ MAS NMR spectrum (where in addition to the aromatic feature(s) at ca. $130 \mathrm{ppm}$ seen in the $500{ }^{\circ} \mathrm{C}$ sample, there are also resonances at ca. $60 \mathrm{ppm}$ and below corresponding to alkyl species.) Thermal volatilisation analysis (TVA) initially developed for the study of polymer degradation [29] has proved most informative in this respect. In this technique, a sample is subjected to temperature programmed heating in vacuo and the condensable evolved gases are collected in a series of traps allowing detailed analysis to be undertaken. The TVA profile for the $300{ }^{\circ} \mathrm{C}$ activated sample is shown in Fig. 8 and contrasts strongly with that 

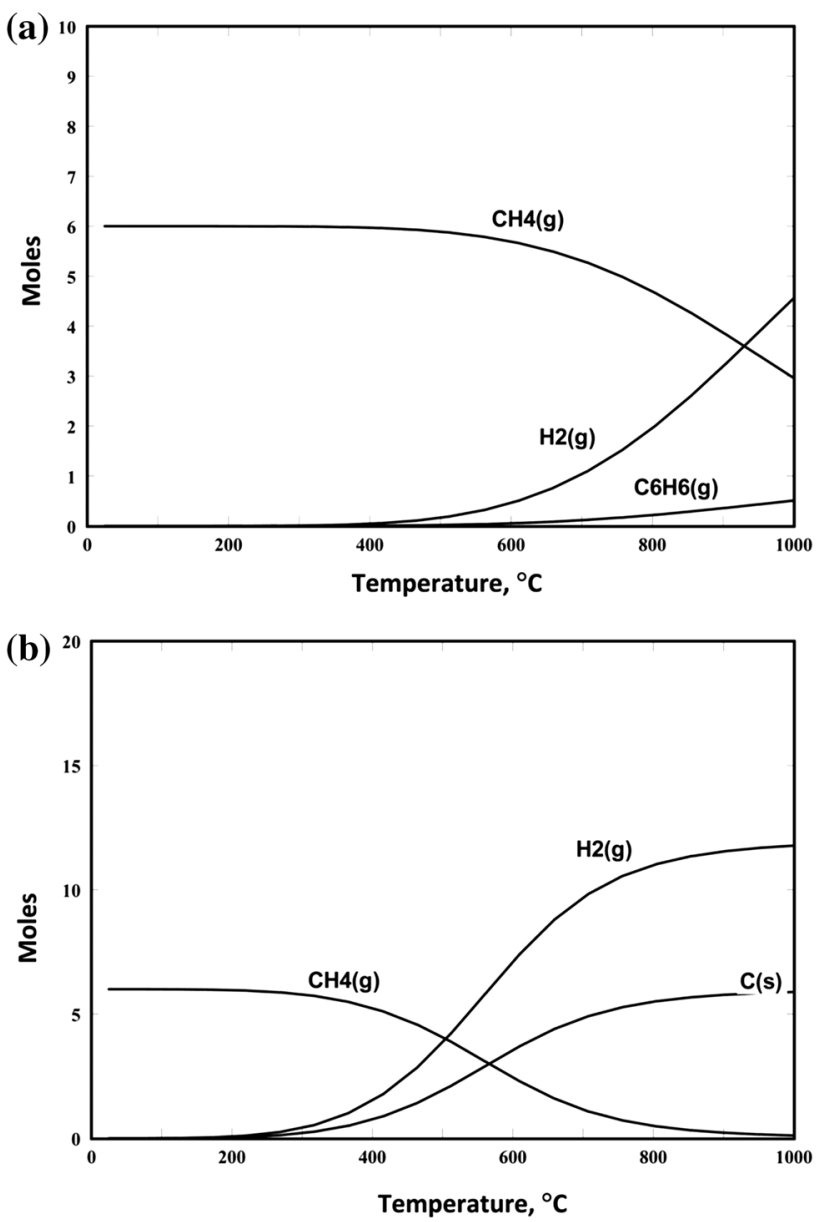

Fig. 7 Equilibrium composition as a function of temperature of reaction mixtures starting from $6 \mathrm{mols} \mathrm{CH}_{4}$ for a methane dehydroaromatisation to produce benzene, and $\mathbf{b}$ methane cracking. Figure reproduced from Ref. [23] with very kind permission from the Royal Society of Chemistry

for the $500{ }^{\circ} \mathrm{C}$ sample as shown in Fig. 9. TVA of the $300{ }^{\circ} \mathrm{C}$ sample removed around $30 \%$ of the retained carbon content (ca. $12 \mathrm{wt} \%$ ) whereas only $9 \%$ was removed in the case of the $500{ }^{\circ} \mathrm{C}$ sample (containing ca. $18 \mathrm{wt} \%$ C). The rich product spectrum of the $300{ }^{\circ} \mathrm{C}$ sample is readily evident although consideration must be given due to the possibility of secondary reactions occurring upon desorption. It is also apparent that some larger species, such as naphthalenes are present which possibly reflect the presence of 12 membered pores in mordenite. To the author's knowledge, this was the first time that TVA has been applied to the characterisation of carbonaceous residues on zeolites. Investigation of the influence of reaction time (Fig. 10) demonstrates the development of the hydrocarbon pool to occur at some point between 2 and 5 min upon stream under the conditions tested, as evidenced by the development of features associated with aromatic species at ca. $130 \mathrm{ppm}$. The precise route towards
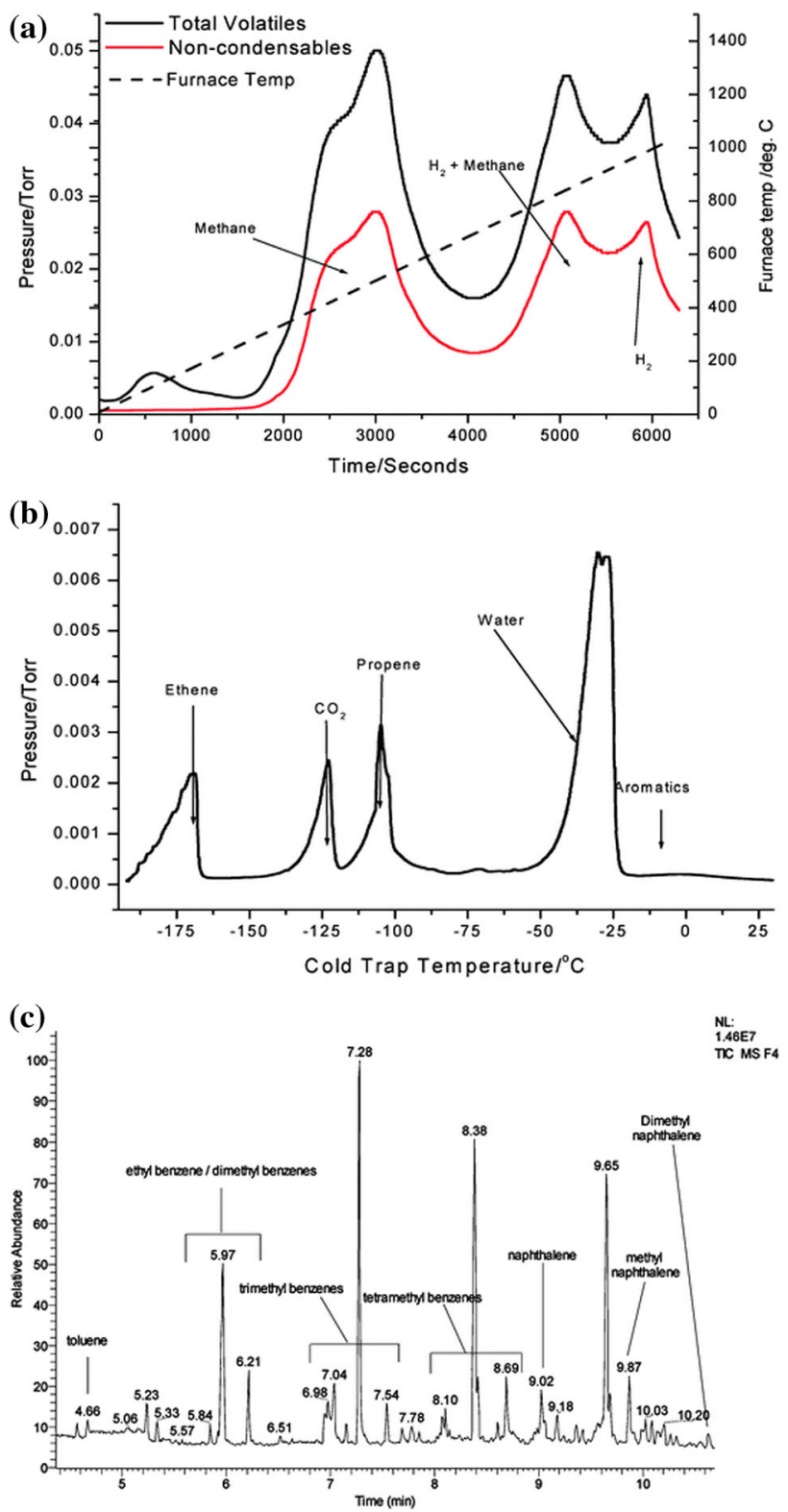

Fig. 8 TVA analysis of H-mordenite coked with methanol for $300 \mathrm{~min}$ on stream at $300{ }^{\circ} \mathrm{C}$ a total volatiles and components not condensed in the liquid $\mathrm{N}_{2}$ trap, b sub-ambient thermal volatilisation analysis of products evolved by warming the liquid $\mathrm{N}_{2}$ trap and c GCMS analysis of the collected liquid fraction. Figure reproduced from Ref. [28] with very kind permission from the Royal Society of Chemistry

the development of the hydrocarbon pool is currently unclear.

\section{The role of binders in zeolite catalysed reactions}

Whilst to date there has only been limited attention to the effect of binders upon zeolite catalysed reactions in the academic literature, there is greater realisation of the often 

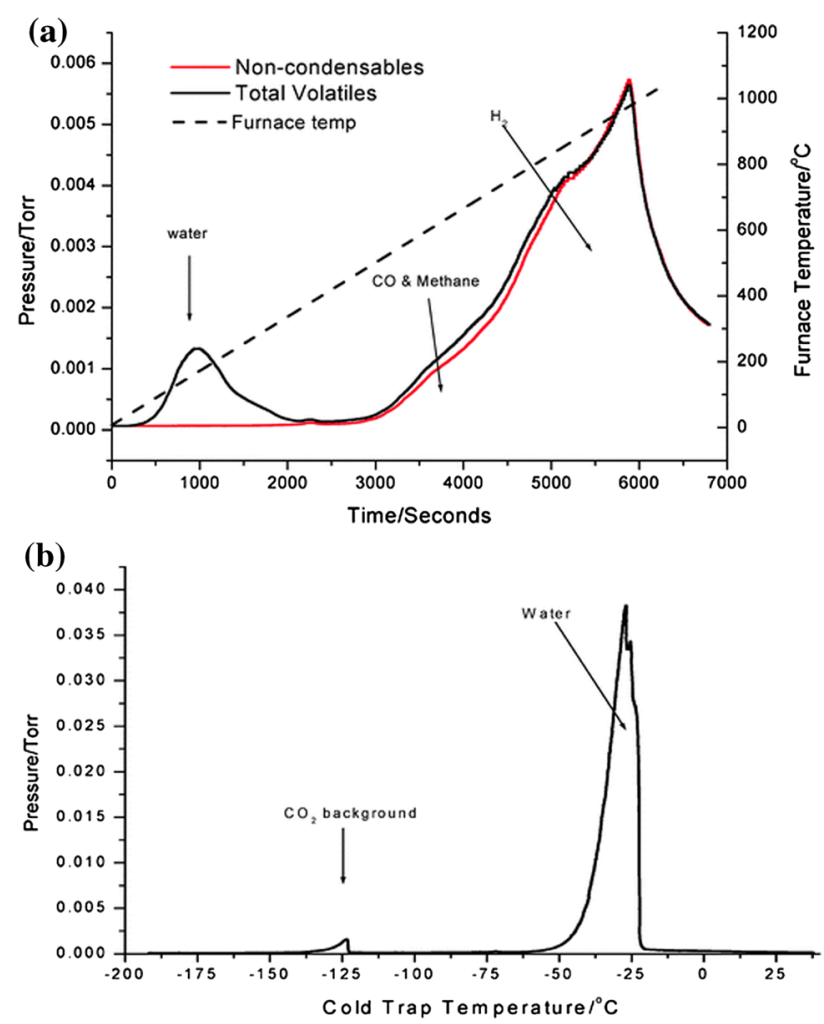

Fig. 9 TVA analysis of H-mordenite coked with methanol for 300 min on stream at $500{ }^{\circ} \mathrm{C}$ a total volatiles and components not condensed in liquid $\mathrm{N}_{2}$ trap and $\mathbf{b}$ sub-ambient thermal volatilisation analysis of products evolved by warming the liquid $\mathrm{N}_{2}$ trap. Figure reproduced from Ref. [28] with very kind permission from the Royal Society of Chemistry

substantial effects that they can have [30-32]. Far from being inert, they can have very significant effects upon coking by, for example, trapping coke precursors. Similarly, they can also prolong catalyst lifetime by entrapment of poisons or modify activity via transfer of chemical species to and from the active phase. Additional potential effects may also relate to the modification of heat transfer or porosity characteristics or improvement of the physical durability of catalysts. A few selected examples of effects documented in the literature follow. In a study involving the application of a kaolinite binder, Misk and co-workers [33] demonstrated it to retard coking of zeolite 5A through entrapment of precursors in reactions involving propene. In terms of transfer of active species, Chang et al. reported that $\alpha$-alumina hydrate binder significantly enhanced the performance of siliceous H-ZSM-5 for a number of reactions, including the conversion of methanol to hydrocarbons through transfer of aluminium species to the ZSM-5 followed by the framework incorporation [34]. Silicon transfer from a silica-alumina binder to LaY zeolite during steaming maintained crystallinity and provided healing during severe steaming [35]. The involvement of binder in

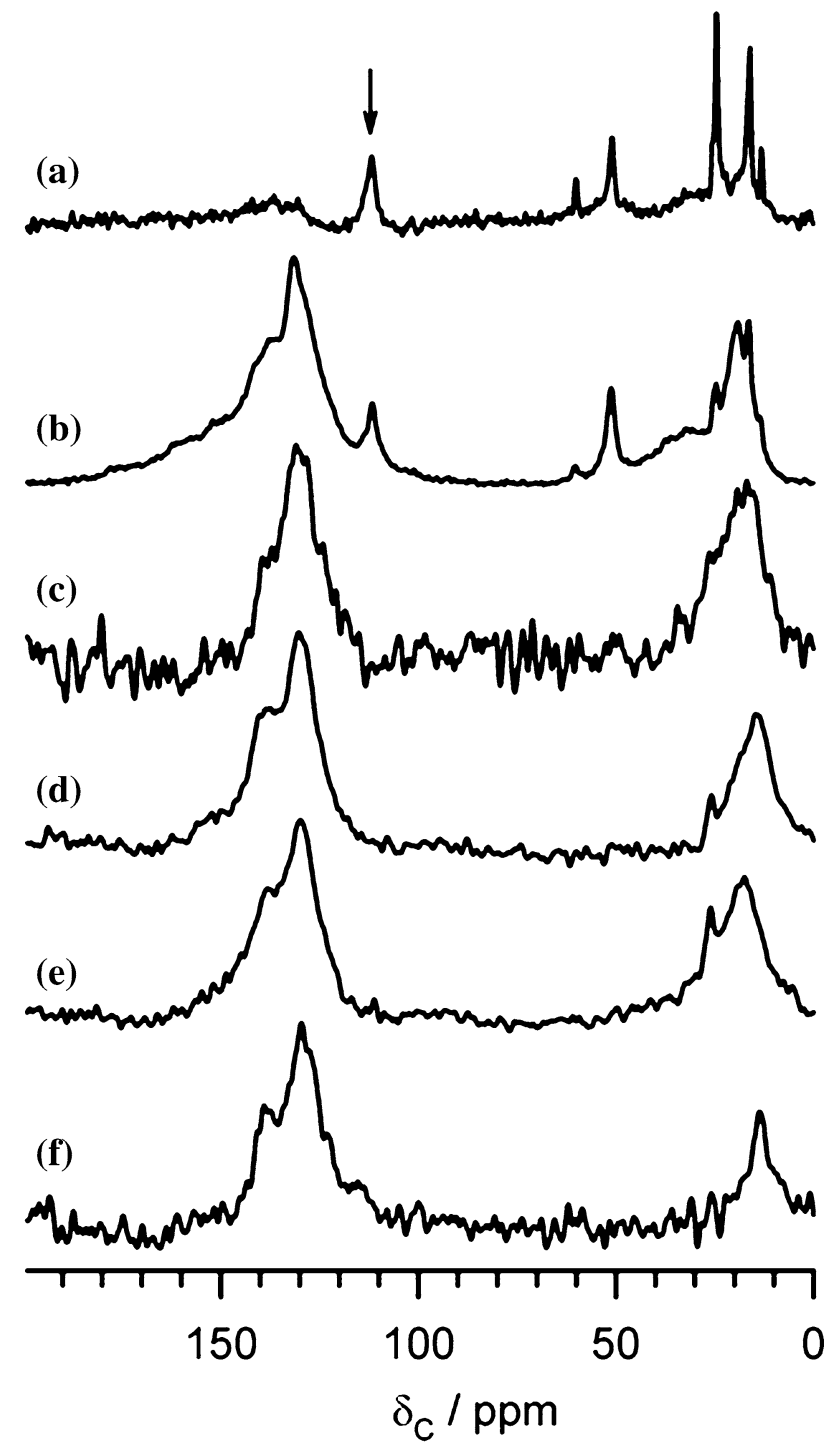

Fig. $10{ }^{13} \mathrm{C}$ MAS NMR spectra of mordenite coked at $300{ }^{\circ} \mathrm{C}$ with methanol as a function of time on stream a direct polarisation spectrum after $2 \mathrm{~min}$ on stream with a $25 \%{ }^{13} \mathrm{C}$ enriched feed, b direct polarisation spectrum after 5 min on stream with a $25 \%{ }^{13} \mathrm{C}$ enriched feed, c cross-polarisation $\left({ }^{1} \mathrm{H}\right)$ after $60 \mathrm{~min}$ on stream, d cross-polarisation $\left({ }^{1} \mathrm{H}\right)$ after $180 \mathrm{~min}$ on stream, e cross-polarisation $\left({ }^{1} \mathrm{H}\right)$ after $420 \mathrm{~min}$ on stream, $\mathbf{f}$ cross-polarisation $\left({ }^{1} \mathrm{H}\right)$ after $600 \mathrm{~min}$ on stream. The arrow indicates the position of the signal arising from the Teflon rotor caps. Figure reproduced from Ref. [28] with very kind permission from the Royal Society of Chemistry

the modification of porosity, and hence, product diffusion and secondary reaction has been documented with a series of bentonite bound Pd containing zeolites applied to the hydroisomerisation of n-octane [36].

It is becoming increasingly apparent that modifications made to improve the performance of zeolite catalysts on a laboratory scale may be more than outweighed by the effects of binders. Therefore, to be meaningful in a truly applied sense, and to prevent waste of effort, the influence 
of such modifications needs to be assessed on catalysts in the final form in which they would be used on a technical scale. The choice of binder will also dramatically influence such effects-with binders derived from clays, aluminas and silicas being amongst the most common (Fig. 10).

\section{Conclusion}

In this brief overview, some aspects of methane dehydroaromatisation, the deposition of carbonaceous residues on mordenite and the application of binders have been very briefly considered. In the case of methane dehydroaromatisation, an alternative strategy to the development of better performing catalysts may involve the modification of highly active methane cracking catalysts. It is somewhat surprising that despite being the major stoichiometric product of reaction, so little attention seems to have been applied to the quantification of hydrogen. In the case of methanol activation over mordenite, the hydrocarbon pool is developed after only 2-5 min on stream at $300{ }^{\circ} \mathrm{C}$ and may comprise some larger aromatic species such as naphthalenes which may be associated with the pore structure related to the $12 \mathrm{mem}$ bered rings. Finally, a brief mention is made of the importance of consideration of the effects of binders in zeolite catalysed reactions which, rather than being inert components of technical catalysts, can exhibit the effects which override those resulting from laboratory scale strategies for improvement.

Open Access This article is distributed under the terms of the Creative Commons Attribution 4.0 International License (http:// creativecommons.org/licenses/by/4.0/), which permits unrestricted use, distribution, and reproduction in any medium, provided you give appropriate credit to the original author(s) and the source, provide a link to the Creative Commons license, and indicate if changes were made.

\section{References}

1. Cejka J, Corma A, Zones S (eds) Zeolites and catalysis, vol 1 and 2. Wiley VCH Weinheim 2010. ISBN 978-3-52732514-6

2. Horn R, Schloegl R (2015) Methane activation by heterogeneous catalysis. Catal Lett 145:23-39

3. Pakhare D, Spivey J (2014) A review of dry $\left(\mathrm{CO}_{2}\right)$ reforming of methane over noble metal catalysts. Chem Soc Rev 43:7813-7837

4. Hutchings GJ, Scurrell MS, Woodhouse JR (1989) Oxidative coupling of methane using oxide catalysts. Chem Soc Rev $18: 251-283$

5. Hall TJ, Hargreaves JSJ, Hutchings GJ, Joyner RW, Taylor SH (1995) Catalytic synthesis of methanol and formaldehyde by partial oxidation of methane. Fuel Proc Technol 42:151-178

6. Ismagilov ZR, Matus EV, Tsikoza LT (2008) Direct conversion of methane on Mo/ZSM-5 catalysts to produce benzene and hydrogen: achievements and perspectives. Energ Env Sci 1:526-541
7. Ma SQ, Guo XG, Zhao LX, Scott S, Bao XH (2013) Recent progress in methane dehydroaromatization: from laboratory curiosities to promising technology. J Energ Chem 22:1-20

8. Wang DJ, Lunsford JH, Rosynek MP (1997) Characterization of Mo/ZSM-5 catalyst for the conversion of methane to benzene. J Catal 169:347-358

9. Lacheen HS, Iglesia $\mathrm{E}$ (2005) Isothermal activation of $\mathrm{Mo}_{2} \mathrm{O}_{5}{ }^{2+}$ ZSM-5 precursors during methane reactions: effect of reaction products on structural evolution and catalytic properties. Phys Chem Chem Phys 7:538-547

10. Liu ST, Wang L, Ohnishi R, Ichikawa M (1999) Bifunctional catalysis of Mo/HZSM-5 in the dehydroaromatization of methane to benzene and naphthalene XAFS/TG/DTA/MASS/FTIR characterization and supporting effects. J Catal 181:175-188

11. Alexander AM, Hargreaves JSJ (2010) Alternative catalytic materials: carbides, nitrides, phosphides and amorphous boron alloys. Chem Soc Rev 39:4388-4401

12. Mckay D, Hargreaves JSJ, Howe RF (2006) XPS evidence for molybdenum nitride formation in ZSM-5. Catal Lett 112:109-113

13. Hargreaves JSJ, Howe RF, Mckay D, Morrison E, Rico JL, Stockenhuber M (2009) Nitridation of $\mathrm{MoO}_{3} / \mathrm{HZSM}-5$ and $\mathrm{Fe}$ $\mathrm{MoO}_{3} / \mathrm{HZSM}-5$. Top Catal 52:1559-1565

14. Ma D, Shu Y, Han X, Liu X, Xu Y, Bao X (2001) Mo/HMCM-22 catalysts for methane dehydroaromatization: a multinuclear MAS NMR study. J Phys Chem B 105:1786-1793

15. Burns S, Hargreaves JSJ, Stockenhuber M, Wells RPK (2007) An Al K-edge EXAFS study of $\mathrm{MoO}_{3} / \mathrm{H}-\mathrm{ZSM}-5$ catalyst precursors. Micropor Mesopor Mater 104:97-102

16. Joyner RW, Smith AD, Stockenhuber M, van den Berg MWE (2004) The local structure of aluminium sites in zeolites. Phys Chem Chem Phys 6:5435-5439

17. Burns S, Hargreaves JSJ, Pal P, Parida KM, Parija S (2006) The effect of dopants on the activity of MoO3/ZSM-5 catalysts for the dehydroaromatisation of methane. Catal Today 114:383-387

18. Liu ST, Dong Q, Ohnishi R, Ichikawa M (1997) Remarkable nonoxidative conversion of methane to naphthalene and benzene on $\mathrm{Co}$ and $\mathrm{Fe}$ modified Mo/HZSM-5 catalysts. Chem Commun $1455-1456$

19. Liu ST, Dong Q, Ohnishi R, Ichikawa M (1998) Unique promotion effect of $\mathrm{CO}$ and $\mathrm{CO} 2$ on the catalytic stability for benzene and naphthalene production from methane on Mo/HZSM-5 catalysts. Chem Commun 1217-1218

20. Ohnishi R, Liu ST, Dong Q, Wang L, Ichikawa M (1999) Catalytic dehydrocondensation of methane with $\mathrm{CO}$ and $\mathrm{CO}_{2}$ toward benzene and naphthalene on Mo/HZSM-5 and Fe/Co-modified Mo/HZSM-5. J Catal 182:92-103

21. Weckhuysen BM, Rosynek MP, Lunsford JH (1998) Characterization if surface carbon formed during the conversion of methane to benzene over Mo/H-ZSM-5 catalysts. Catal Lett 52:31-36

22. Burns S, Gallagher JG, Hargreaves JSJ, Harris PJF (2007) Direct observation of carbon nanotube formation in Pd/H-ZSM-5 and $\mathrm{MoO}_{3} / \mathrm{H}-\mathrm{ZSM}-5$ based methane activation catalysts. Catal Lett 116:122-127

23. Spivey JJ, Hutchings GJ (2014) Catalytic aromatization of methane. Chem Soc Rev 43:792-803

24. Stocker M (1999) Methanol-to-hydrocarbons: catalytic materials and their behavior. Micropor Mesopor Mater 29:3-48

25. Olsbye U, Svelle S, Bjorgen M, Beato P, Janssens TVW, Joensen F, Bordiga S, Lillerud KP (2012) Conversion of methanol to hydrocarbons: how zeolite cavity and pore size controls product selectivity. Angew Chemie Int Edn 51:5810-5831

26. Olsbye U, Svelle S, Lillerud KP, Wei ZH, Chen YY, Li JF, Wang JG, Fan WB (2015) The formation and degradation of active species during methanol conversion over protonated zeotype catalysts. Chem Soc Rev 44:7155-7176 
27. Lesthaeghe D, Horre A, Waroquier M, Marin GB, van Speybroeck V (2009) Theoretical insights in methylbenzene side-chai growth in ZSM-5 zeolites for methanol to olefin conversion. Chem Eur J 25:10803-10808

28. France LJ, Apperley DC, Ditzel EJ, Hargreaves JSJ, Lewicki JP, Liggat JJ, Todd D (2011) An investigation of the nature and reactivity of carbonaceous species deposited on mordenite by reaction with methanol. Catal Sci Technol 1:932-939

29. Lecomte HA, Liggat JJ (2006) Degradation mechanism of diethylene glycol units in a terephthalate polymer. Polymer Degrad Stab 91:681-689

30. Hargreaves JSJ, Munnoch AL (2013) A survey of the influence of binders in zeolite catalysis. Catal Sci Technol 3:1165-1171

31. Michels NL, Mitchell S, Perez-Ramirez J (2014) Effects of binders on the performance of shaped hierarchical MFI zeolites in methanol-to-hydrocarbons. ACS Catal 4:2409-2417

32. Whiting GT, Meirer F, Valencia D, Mertens MM, Bons AJ, Weiss BM, Stevens PA, de Smit E, Weckhuysen BM (2014)
Selective staining of Bronsted acidity in zeolite ZSM-5-based catalyst extrudates using thiophene as a probe. Phys Chem Chem Phys 16:21531-21542

33. Misk K, Joly G, Magnoux P, Guisnet M, Jullian S (2000) Formation of coke from propene over 5A adsorbents-influence of the binder on coke composition, location and removal. Micropor Meospor 40:197-204

34. Shihabi DS, Garwood WE, Chu P, Miale JM, Lago RM, Chu CTW, Chang CD (1985) Aluminum insertion into high-silica zeolite frameworks: II Binder activation of high-silica ZSM-5. J Catal 93:471-474

35. Gelin P, Des Couriers T (1991) Role of amorphous matrix in the hydrothermal aging of fluid catalytic cracking catalysts. Appl Catal 72:179-192

36. de Luca A, Valverde JL, Sanchez P, Dorado F, Ramos MJ (2004) Influence if the binder on the $n$-octane hydroisomerization over palladium-containing zeolite catalysts. Ind Eng Chem Res 43:8217-8225 